\title{
Evidência sorológica da infecção aguda pelo Toxoplasma gondii em gestantes de Cascavel, Paraná
}

\author{
Serological evidence of acute Toxoplasma gondii infection \\ in pregnant women in Cascavel, Paraná
}

\author{
Sônia de Lucena Mioranza ${ }^{1,2}$, Luciana Regina Meireles ${ }^{1}$, Eduardo Luís Mioranza ${ }^{3}$ \\ e Heitor Franco de Andrade Júnior ${ }^{1}$
}

\begin{abstract}
RESUMO
Para verificar a ocorrência da toxoplasmose em Cascavel, Paraná, cidade próxima a região onde ocorreu o maior surto epidêmico descrito mundialmente, 334 amostras de soros de gestantes foram triadas pelo ensaio imunoenzimático comercial IgG no Laboratório Municipal de Cascavel, e confirmadas no Instituto de Medicina Tropical de São Paulo por imunofluorescência IgG, ensaio imunoenzimático e avidez de IgG in house. A soropositividade pelo IgG comercial foi 54,2\%, pela imunofluorescência 54,8\% e pelo IgG in bouse 53,9\%, com boa concordância entre imunofluorescência/IgG comercial (Kappa=0,963781; co-positividade=97,8\%; co-negatividade=98,7\%) e imunofluorescência/lgG in house (Kappa=0,975857; c0-positividade=97,8\%; co-negatividade $=100 \%)$. A evidência de infecção aguda nas gestantes foi similar tanto pela avidez de $\operatorname{IgG}(2,4 \%$ ao ano $)$ como pela análise estatística de tendência (teste $\chi^{2}$ ) por faixa etária ( $2 \%$ ao ano), sugerindo que a triagem sorológica pré-natal e a vigilância epidemiológica são imprescindíveis para redução do risco da toxoplasmose na região, embora sem evidência de surto epidêmico.
\end{abstract}

Palavras-chaves: Toxoplasma gondii. Imunodiagnóstico. Avidez de IgG.

\begin{abstract}
In order to investigate the incidence of toxoplasmosis in Cascavel, Paraná, a city near the region where the largest reported epidemic outbreak in the world occurred, 334 serum samples from pregnant women were screened using a commercial IgG immunoenzymatic assay at the Municipal Laboratory in Cascavel and were confirmed at the Institute of Tropical Medicine in São Paulo, by means of IgG immunofluorescence, immunoenzymatic assaying and the in-house IgG avidity test. The IgG seropositivity from the commercial test was $54.2 \%$, from immunofluorescence $54.8 \%$ and from the in-house $\operatorname{IgG} 53.9 \%$, with good agreement between immunofluorescence and the commercial IgG test ( $\mathrm{kappa}=0.963781$; co-positivity $=97.8 \%$; co-negativity $=98,7 \%$ ) and between immunofluorescence and the in-house IgG (kappa $=0.975857$; co-positivity $=97.8 \%$; co-negativity $=100 \%)$. The evidence of acute infection among the pregnant women was similar, as estimated both by $\operatorname{IgG}$ avidity $(2.4 \% / \mathrm{year})$ and by statistical trend analysis $\left(\chi^{2}\right.$ test) according to age group (2\%/year). This suggests that prenatal serological screening and epidemiological surveillance are essential for reducing the risk of toxoplasmosis in the region, although without evidence of an epidemic outbreak.
\end{abstract}

Key-words: Toxoplasma gondii. Immunodiagnosis. IgG avidity.

A toxoplasmose, infecção causada pelo parasita Toxoplasma gondii ${ }^{115}$, é especialmente importante na infecção congênita e reativação em imunodeprimidos ${ }^{26}$, sendo geralmente assintomática ou associada a manifestações inespecíficas em indivíduos imunocompetentes ${ }^{30}$.

A primo-infecção na gravidez pode afetar o feto, com severas complicações, como nascimento prematuro, dano neurológico permanente e comprometimento visual ${ }^{2031}$. A frequiência e severidade da infecção congênita dependem do período gestacional ${ }^{12} \mathrm{e}$ do diagnóstico precoce para intervenção terapêutica específica ${ }^{34}$ e redução do risco de infecção fetal.
Para o diagnóstico da infecção pelo Toxoplasma gondii, os testes sorológicos de imunofluorescência indireta, aglutinação e imunoenzimáticos são os métodos mais freqüentemente utilizados para pesquisa de anticorpos específicos como IgM e/ou IgA e/ou aumento significante do nível de anticorpos $\operatorname{Ig} G^{241}$.

Contudo, o diagnóstico sorológico da toxoplasmose é muito complexo e tem sido discutido extensivamente na literatura, especialmente em gestantes ${ }^{31}$. Os resultados devem ser interpretados com cautela ${ }^{46}$, porque tanto a IgA ${ }^{18}$ quanto a IgM podem persistir por anos, levando a erro na determinação da época da infecção materna ${ }^{24} \mathrm{e}$ falha no diagnóstico da infecção aguda na gestante ${ }^{22}$.

\footnotetext{
1. Instituto de Medicina Tropical de São Paulo, São Paulo, SP. 2. Universidade Estadual do Oeste do Paraná, Cascavel, PR. 3. Laboratório Municipal de Cascavel, Cascavel, PR. Endereço para correspondência: Dra. Sônia de Lucena Mioranza. Rua Dr. Enéas de Carvalho Aguiar 470/1ªndar, Cerqueira César, 05403-000 São Paulo-SP. Tel: 5511 3061-7010/8591-2594

e-mail: smioranza@usp.br

Recebido para publicação em 29/05/2008

Aceito em 29/10/2008
} 
Por estas razões tem sido sugerido por diversos autores ${ }^{20} 333640$ a utilização de um painel de testes como o procedimento mais adequado para o diagnóstico da infecção aguda pelo Toxoplasma gondii. Estes testes são utilizados especialmente em países que apresentam alta prevalência da infecção como Brasil ${ }^{3}$, Kuwait ${ }^{23}$, República Democrática de São Tomé e Príncipe ${ }^{13}$, Trinidade e Tobago ${ }^{1}$.

Durante a resposta imune, a afinidade com que os anticorpos IgG ligam-se a seus antígenos pode ser avaliada pela menor ou maior facilidade de quebra dessa ligação $0^{14}$, onde as populações de IgG apresentam diferentes afinidades, resultando numa baixa ou alta avidez pelo antígeno ${ }^{23}$ que pode ser avaliada pelo ensaio imunoenzimático de avidez.

0 teste de avidez de IgG vem sendo utilizado, especialmente no diagnóstico da toxoplasmose aguda da gestante ${ }^{26}$, identificando o mais provável período de infecção, discriminando as infecções agudas das crônicas com apenas uma amostra de soro ${ }^{43}$. Apesar de auxiliar o diagnóstico da infecção recente e pregressa pelo Toxoplasma, a baixa avidez pode persistir por até um ano em alguns $\operatorname{casos}^{35}$, e não deve ser avaliada isoladamente ${ }^{8}$, já que pode ser erroneamente interpretada no diagnóstico individual ${ }^{32}$, ressaltando a importância da utilização de um painel de testes sorológicos para uma maior probabilidade de acerto no diagnóstico da infecção.

A determinação da prevalência da toxoplasmose em Cascavel, município da região Oeste do Paraná é de extrema importância já que neste estado foi registrado em 2001 o maior surto mundial da doença atribuído à contaminação do reservatório de água com oocistos de Toxoplasma gondii ${ }^{10}$.

Este estudo teve como objetivo verificar a ocorrência da toxoplasmose em gestantes de Cascavel, avaliando a performance de diferentes testes no estabelecimento do perfil sorológico da infecção.

\section{MATERIAL E MÉTODOS}

Amostras coletadas. 0 estudo transversal desenvolveuse com amostras de soro únicas de 334 gestantes com idade gestacional desconhecida e faixa etária entre 14 e 43 anos atendidas no Laboratório Municipal de Cascavel-PR, provenientes do Sistema Único de Saúde-SUS, no período de dezembro de 2005 a fevereiro de 2006. A pesquisa de anticorpos IgG antiToxoplasma gondii foi previamente estabelecida no laboratório citado e, posteriormente, as amostras foram testadas em ensaios complementares (ensaio imunoenzimático-ELISA e imunofluorescência indireta-IFI) controlados no Laboratório de Protozoologia do Instituto de Medicina Tropical de São Paulo. 0 projeto foi aprovado pelo Comitê de Ética em Pesquisa com Seres Humanos do Instituto de Ciências Biomédicas (ICB) da Universidade de São Paulo (USP), da Universidade Estadual do Oeste do Paraná (UNIOESTE) e do Instituto de Medicina Tropical de São Paulo (IMTSP).

Pesquisa de anticorpos. Ensaio imunoenzimático IgG Comercial-PR: anticorpos IgG anti-Toxoplasma gondii foram determinados no Laboratório Municipal de Cascavel pelo ensaio comercial imunoenzimático (BTI-Bio Tecnologia Industrial ${ }^{\circledR}$, Belo Horizonte-MG) de acordo com as instruções do fabricante. Os resultados foram expressos em Unidades Internacionais por mililitros, sendo considerados positivos aqueles com títulos superiores a $10 \mathrm{UI} / \mathrm{ml}$.

Imunofluorescência indireta IgG e IgM: a pesquisa dos anticorpos IgG anti-Toxoplasma gondii pela IFI, considerado como teste de referência, foi realizada segundo Camargo \& Leser ${ }^{6}$. Lâminas sensibilizadas com taquizoítos da cepa RH, produzidas no laboratório de protozoologia do IMTSP, receberam diluições seriadas de soro, sendo incubadas a $37^{\circ} \mathrm{C}$, em câmara úmida, por 30 minutos. Após lavagens com PBS ( $\mathrm{NaCl}$ 0,15M tampão $\mathrm{NaPO}_{4}$ $0,01 \mathrm{M} \mathrm{pH} 7.2)$, foram recobertas com o conjugado marcado com fluoresceína anti-IgG humano (1/400, Sigma $\left.{ }^{\circledR}\right)$ em Azul de Evans e incubadas por mais 30 minutos. Após lavagens com PBS, as lâminas foram analisadas em microscópio de epifluorescência (Zeiss Axioskop ${ }^{\circledR}$ ). A reação foi considerada positiva quando os taquizoítos apresentaram uma clara fluorescência verde na membrana celular e como negativa pela ausência de fluorescência ou apenas na extremidade dos parasitas (fluorescência polar). Para realização da IgM nas amostras de gestantes com baixa avidez foi usada a metodologia citada e conjugado marcado com fluoresceína anti-IgM humano $\left(1 / 800\right.$, Sigma $\left.^{\circledR}\right)$.

Ensaio imunoenzimático IgG e IgM in house: anticorpos IgG anti-Toxoplasma gondii foram determinados pela metodologia de Venkatesan \& Wakelin ${ }^{45}$. Placas de poliestireno para microtitulação $\left(\right.$ Costar $\left.^{\circledR}\right)$ foram sensibilizadas com extrato antigênico solúvel de Toxoplasma gondii em tampão carbonato bicarbonato $0,1 \mathrm{M} \mathrm{pH} 9.5$ na concentração de $1 \mu \mathrm{g} / \mathrm{ml}$ de antígeno. Após 24 horas a $4^{\circ} \mathrm{C}$ em câmara úmida, as placas lavadas 5 vezes com PBS, contendo 0,05\% de Tween 20 (PBST) foram bloqueadas com $0,3 \%$ de solução de leite desnatado $\left(\right.$ Molico $\left.^{\circledR}\right)$ em PBST a $37^{\circ} \mathrm{C}$ por 1 hora e estocadas a $-20^{\circ} \mathrm{C}$. Duplicatas de diluição 1/100 de cada amostra de soro em PBST, contendo 0,3\% de leite desnatado foram adicionadas nas placas e incubadas a $37^{\circ} \mathrm{C}$ por 1 hora. Após lavagens, foi adicionado o conjugado peroxidase anti-IgG humano diluído (1/20.000, Sigma $\left.{ }^{\circledR}\right)$ e incubado por 1 hora a $37^{\circ} \mathrm{C}$. A reação foi revelada pela adição de $0 P D 0,4 \mathrm{mg} / \mathrm{ml}$ e $\mathrm{H}_{2} \mathrm{O}_{2} 0,03 \%$ em citrato de sódio $0,05 \mathrm{M}$ pH 5.8 por 30 minutos e bloqueada pela adição de $\mathrm{HCl} 4 \mathrm{~N}$. A densidade óptica a 492nm foi determinada por leitor automático de microplacas (Labsystems Multiskan MS). Para a IgM foi usada a mesma metodologia com conjugado anti-IgM imunoenzimático marcado com peroxidase $\left(1 / 5000\right.$, Sigma $\left.^{\circledR}\right)$.

Avidez de IgG: foi utilizado o mesmo procedimento para pesquisa de IgG pelo ELISA in house, sendo baseado na metodologia de Hedman e cols ${ }^{21}$. Na adsorção da placa, 100 $\mu 1$ de antígeno protéico de Toxoplasma gondii, 1 $\mu \mathrm{g} / \mathrm{ml}$, em solução caotrópica neutra de Uréia $8 \mathrm{M}$ contendo tampão fosfato $0,02 \mathrm{M} \mathrm{pH}$ 7,2 (PBS) foi colocado em cada poço por 24 horas a $4^{\circ} \mathrm{C}$. Após bloqueio de eventuais sítios livres como descrito no ELISA IgG, foram colocados em poços quadruplicados $100 \mu 1$ de diluições das amostras de soro em PBST (1/100, 1/200, 1/400, 1/800), e as placas foram incubadas por 1 hora a $37^{\circ} \mathrm{C}$ e lavadas 5 vezes 
com PBST. Para cada diluição, dois poços receberam incubação adicional de 10 minutos a $37^{\circ} \mathrm{C}$ com solução caotrópica neutra de uréia 6M contendo PBS 0,02M pH 7.2, sendo os outros dois poços controles mantidos em PBST. A seguir, foi feita a revelação do anticorpo ligado por conjugado peroxidase anti-IgG humano como acima descrito. A estimativa do título efetivo de cada soro foi feita através da associação dos valores das diluições isoladas de cada amostra num modelo log-log de regressão linear ${ }^{25}$. Os títulos de anticorpos totais ou com alta avidez, resistentes ao caotrópico, foram obtidos através de regressão log-log, utilizandose os valores capazes de gerar absorbância 1.0 no ELISA ( $\log =0$ ). A avidez foi determinada pela porcentagem de título resistente ao caotrópico (AVT) e amostras cujos valores de AVT eram maiores que $30 \%$ foram considerados de alta avidez.

Análise estatística. A análise estatística dos dados foi feita mediante a comparação das frequiências e títulos dos ensaios pelo Teste de Kappa, índices de sensibilidade e especificidade. 0 teste de tendência do qui-quadrado $\left(\chi^{2}\right)$ foi utilizado para avaliação da incidência por proporção de amostras positivas em faixas etárias determinadas, assumindo a prevalência mínima ao nascimento. Os testes foram feitos utilizando-se o conjunto estatístico GraphPad Prism 3.0 e Epiinfo 6.0.

\section{RESULTADOS}

Para pesquisa de anticorpos anti-Toxoplasma gondii amostras de soros de 334 gestantes foram submetidas à triagem prévia no Paraná (ELISA IgG comercial) e análises complementares em São Paulo. A correlação dos resultados obtidos nos ensaios imunoenzimáticos no Paraná e em São Paulo pode ser verificada na Figura 1, onde se observa 3 resultados discordantes, 2 positivos pelo ELISA IgG comercial enegativos pelo ELISA IgG in house e 1 resultado negativo pelo ELISA IgG comercial e positivo pelo ELISA IgG in house. Comparando-se os ensaios enzimáticos $\operatorname{IgG}$ comercial e in bouse entre si observou-se uma boa concordância (Kappa $=0,981918$ ), sensibilidade de 99,4\% (IC 95\%:96,5-100) e especificidade de 98,7\% (IC 95\%:94,9-99,8), sendo os valores preditivo positivo 98,9\% (IC 95\%:95,6-99,8) e negativo 99,3\% (IC 95\%:95,9-100).

De acordo com a IFI, teste de referência, a prevalência foi $54,8 \%$, similar a encontrada nos dois ensaios imunoenzimáticos. No ELISA IgG comercial, observou-se 181 amostras positivas correspondente a uma prevalência de 54,2\% e no ELISA IgG in house, 180 amostras positivas com 53,9\% de prevalência (dados não mostrados).

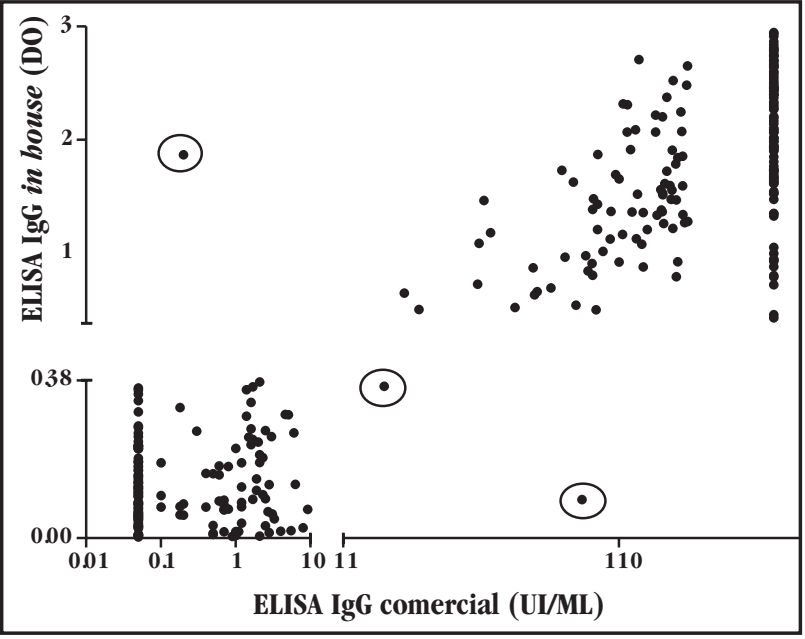

Figura 1 - Comparação da reatividade quantitativa para IgG anti Toxoplasma gondii em 334 amostras de soro de gestantes de Cascavel-PR, utilizando-se os ensaios ELISA IgG in house e ELISA IgG comercial. As interrupções dos eixos apresentam os limiares de positividade dos ensaios e os círculos representam as amostras discordantes entre os testes.

A confirmação e comparação dos resultados dos testes sorológicos para IgG obtidos pelos métodos IFI IgG, ELISA IgG in house e ELISA IgG comercial estão apresentados na Tabela 1, observando-se uma boa concordância entre os 3 métodos. Quando a IFI IgG foi comparada com o ELISA IgG in house houve uma maior concordância (Kappa=0,975857) com alta sensibilidade de 97,8\% (IC 95\%:94,2-99,3), especificidade de 100\% (IC 95\%:96,9-100), valor preditivo positivo de 100\% (IC 95\%:97,4-100) e valor preditivo negativo de 97,4\% (IC 95\%:93,1-99,2). Quando comparados a IFI IgG e o ELISA IgG comercial os resultados mostraram uma boa concordância (Kappa=0,963781), sensibilidade de 97,8\% (IC 95\%:94,1-99,3), especificidade de 98,7\% (IC 95\%: 94,8-99,8), 98,9\% de valor preditivo positivo (IC 95\%:95,6-98,8) e 97,4\% de valor preditivo negativo (IC 95\%: 93,0-99,2).

As amostras de soros de gestantes com sorologia positiva no ELISA IgG in house $(\mathrm{n}=180)$ foram submetidas ao teste de avidez de IgG. Destas gestantes, $6(3,3 \%)$ apresentaram baixa avidez de IgG, indicativo de infecção adquirida recentemente e 174 (96,7\%) gestantes com alta avidez, indicativo de infecção adquirida há mais tempo. Os dados evidenciam uma distribuição bimodal dos soros, observando-se que a grande maioria das infecções não é recente, pois neste estudo valores de AVT maiores que $30 \%$ foram considerados de alta avidez (Figura 2).

Tabela 1 - Distribuição da soropositividade dos anticorpos IgG anti-Toxoplasma gondii pela IFI IgG (teste de referência), ELISA IgG comercial e ELISA IgG in house, em 334 amostras de soro de gestantes de Cascavel-PR, com índices sorológicos de cada ensaio.

\begin{tabular}{|c|c|c|c|c|c|c|c|}
\hline \multirow[b]{2}{*}{ Teste } & \multirow[b]{2}{*}{ Resultado } & \multicolumn{2}{|c|}{ IFI IgG } & \multirow{2}{*}{$\begin{array}{c}\text { Sensibilidade (IC 95\%) } \\
\text { co-negatividade }\end{array}$} & \multirow{2}{*}{$\begin{array}{c}\text { Especificidade (IC 95\%) } \\
\text { co-positividade }\end{array}$} & \multirow{2}{*}{$\begin{array}{c}\text { Valo preditivo } \\
\text { positivo (IC 95\%) }\end{array}$} & \multirow{2}{*}{$\begin{array}{c}\text { Valo preditivo } \\
\text { negativo (IC 95\%) }\end{array}$} \\
\hline & & positivo & negativo & & & & \\
\hline ELISA IgG & positivo & 179 & 2 & $97,8 \%$ & $98,7 \%$ & $98,9 \%$ & $97,4 \%$ \\
\hline $\begin{array}{l}\text { comercial } \\
(\mathbf{k}=\mathbf{0 , 9 6 3 7 8 1 )})\end{array}$ & negativo & 4 & 149 & $(94,1-99,3)$ & $(94,8-99,8)$ & $(95,6-98,8)$ & $(93-99,2$ \\
\hline ELISA IgG & positivo & 180 & 0 & $97,8 \%$ & $100,0 \%$ & $100,0 \%$ & $97.4 \%$ \\
\hline $\begin{array}{l}\text { in house } \\
(\mathbf{k}=\mathbf{0 , 9 7 5 8 5 7 )}\end{array}$ & negativo & 4 & 150 & $(94,2-99,3)$ & $(96,9-100)$ & $(97,4-100)$ & $(93,1-99,2)$ \\
\hline
\end{tabular}

IgG: imunoglobulina G, ELISA: ensaio imunoenzimático, IFI: imunofluorescência indireta, IC: intervalo de confiança, k: kappa. 


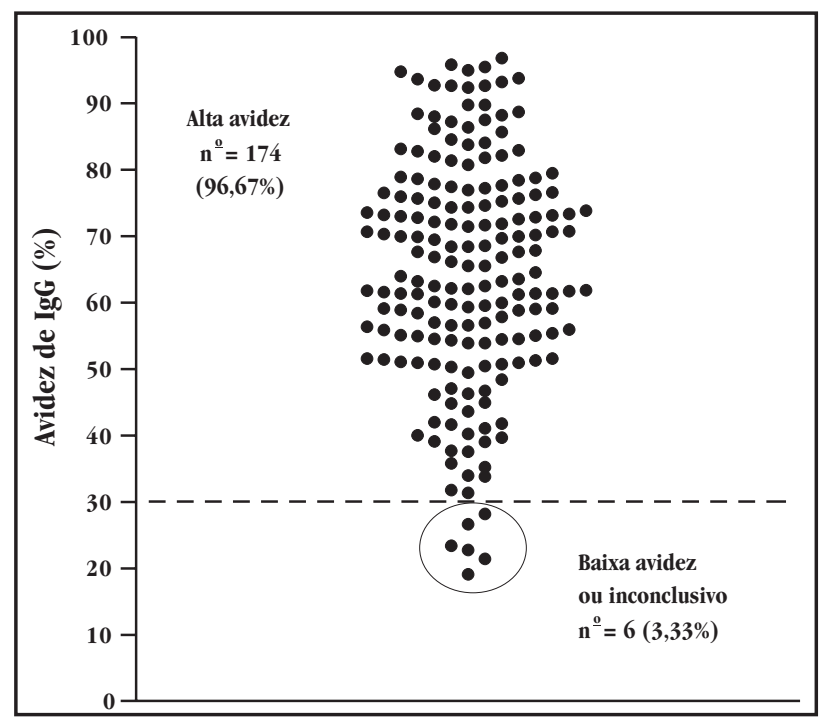

Figura 2 - Avidez de IgG em 180 amostras de soro de gestantes de Cascavel-PR, com sorologia positiva para Toxoplasma gondii, expressa em porcentagem de avidez de anticorpos IgG. A linha tracejada mostra o limiar utilizado para definição de baixa avidez ou infecção recente.

A Tabela 2 mostra a determinação do perfil sorológico individual de 6 gestantes que apresentaram baixa avidez no ELISA IgG in house e os resultados pelos diferentes testes utilizados.
Duas amostras foram negativas para IgM tanto pela IFI como pelo ELISA, mostrando discordância com os resultados da avidez, e, portanto, com perfil sorológico inconclusivo. As demais amostras apresentaram baixa avidez e positividade para IgM pela IFI, sugerindo infecção aguda. Destas, apenas uma amostra apresentou-se positiva para IgM pela IFI e negativa pelo ELISA.

Neste estudo a incidência da toxoplasmose foi estimada diretamente a partir da avidez de IgG, onde observa-se que das 334 gestantes, 4 apresentaram resultados sugestivos de infecção aguda, com uma incidência de 1,2\% (IC 95\%:0,4-3,2\%), que resulta numa incidência anual de $2,4 \%$ de infecção na população, avaliando-se o período de medida do pré-natal, em geral de 6 meses.

A incidência da toxoplasmose também foi determinada indiretamente pela análise de soropositividade a partir das faixas etárias de 334 gestantes, estimando-se uma incidência de $2 \%$ ao ano, pelo teste estatístico de tendência $\left(\chi^{2}\right)$. De acordo com os dados verificou-se um aumento crescente e organizado do título de anticorpos em relação à idade, ou seja, tempo de exposição ao agente, sem alterações discrepantes em grupos etários, características de surtos epidêmicos (Figura 3).

Tabela 2 - Perfis sorológicos de 6 gestantes de Cascavel-PR que apresentaram baixa avidez de IgG de acordo com diferentes testes empregados.

\begin{tabular}{|c|c|c|c|c|c|c|c|c|}
\hline \multirow{2}{*}{$\begin{array}{l}\text { Idade } \\
\text { anos }\end{array}$} & \multirow{2}{*}{$\begin{array}{c}\operatorname{IgG}^{\mathrm{a}} \text { ELISA } \\
\text { comercial }(\mathrm{UI} / \mathrm{ml})\end{array}$} & \multirow{2}{*}{$\begin{array}{c}\operatorname{IgG}^{\mathrm{b}} \text { ELISA } \\
(\mathrm{UA} / \mathrm{ml}) \\
\end{array}$} & \multirow{2}{*}{$\begin{array}{c}\operatorname{IgM}^{\mathrm{c}} \text { ELISA } \\
\text { (D0) }\end{array}$} & \multicolumn{2}{|c|}{ IFI } & \multirow{2}{*}{$\begin{array}{l}\text { AVT } \\
(\%) \\
\end{array}$} & \multirow[b]{2}{*}{ Interpretaçãa ${ }^{\mathrm{d}}$} & \multirow{2}{*}{$\begin{array}{c}\text { Perfil } \\
\text { sorológico }\end{array}$} \\
\hline & & & & IgG & IgM & & & \\
\hline 28 & 130,0 & 546 & 0,122 & positivo & positivo & 23,4 & baixa avidez & fase aguda \\
\hline 38 & $>200,0$ & 2.701 & 0,168 & positivo & positivo & 21,4 & baixa avidez & fase aguda \\
\hline 32 & 117,6 & 4 & 0,078 & positivo & positivo & 26,6 & baixa avidez & fase aguda \\
\hline 32 & 33,8 & 28 & 0,059 & positivo & negativo & 19,1 & baixa avidez & inconclusivo \\
\hline 22 & 102,2 & 90 & 0,167 & positivo & positivo & 22,8 & baixa avidez & fase aguda \\
\hline 27 & 187,1 & 105 & 0,082 & positivo & negativo & 28,2 & baixa avidez & inconclusivo \\
\hline
\end{tabular}

${ }^{\mathrm{a}}$ Positivo: $>10 \mathrm{UI} / \mathrm{ml},{ }^{\mathrm{b}}$ cut off $=2 \mathrm{UA},{ }^{{ }^{c}}$ ut off $=0,114,{ }^{\mathrm{d}}$ baixa avidez de $\operatorname{IgG}:<30 \%$, ${ }^{\mathrm{e}}$ perfil I: fase aguda.

IgG: imunoglobulina G, IgM: imunoglobulina M, ELISA: ensaio imunoenzimático, UI/ml: unidades internacionais por mililitros, UA/ml: unidades arbitrárias por mililitros, DO: densidade óptica, IFI: imunofluorescência indireta, AV'T: avidez por título.

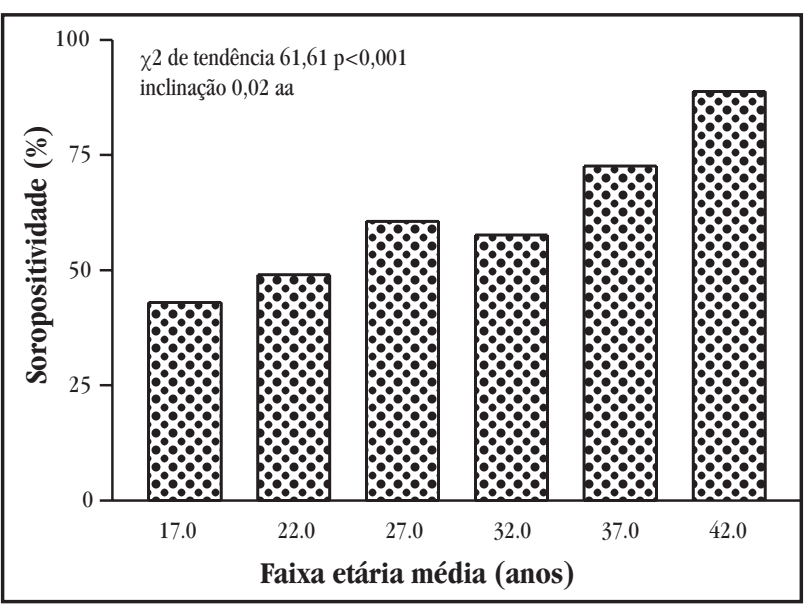

Figura 3 - Evolução da prevalência sorológica da toxoplasmose por faixa etária, em percentual, determinada pela IFI IgG, em 334 amostras de soro de gestantes de Cascavel-PR. Através da análise do teste de tendência $\chi^{2}$ (qui-quadrado) estimou-se uma incidência de $2 \%$ ao ano.

\section{DISCUSSÃo}

A pesquisa de anticorpos IgG anti-Toxoplasma gondii, utilizando amostra única de soro pelo ELISA IgG comercial, mostrou uma prevalência de $54,2 \%$ da doença nas gestantes. No Brasil, estudos realizados com grávidas evidenciaram $67 \%$ de positividade em Londrina- $\mathrm{PR}^{37}$, e outras regiões de mesmo padrão social, também mostraram prevalência equivalente, como 59,8\% em Porto Alegre-RS ${ }^{44}, 51,6 \%$ em Uberlândia- $\mathrm{MG}^{16}$ e 71,4\% em São Bernardo do Campo-SP' ${ }^{16}$.

0 encontro de anticorpos IgG anti-Toxoplasma gondii em amostra única de soro, indica apenas que houve exposição ao agente, sem definição do período que a infecção foi adquirida ${ }^{36}$. Além disso, a presença de IgM ou IgG durante a gestação não pode ser usada para definir se a infecção é aguda ou crônica ${ }^{39}$.

Os dados de prevalência no Paraná foram confirmados em São Paulo pelo teste de referência IFI IgG com 54,8\% de amostras 
positivas e pelo ELISA IgG in bouse com $53,9 \%$, havendo grande concordância entre os testes, um fato nem sempre observado entre ensaios com diferentes antígenos como a IFI e a hemaglutinaçã̃ $0^{14}$. Contudo, os diferentes ensaios confirmam a infecção e a alta prevalência na fase reprodutiva, achados condizentes com outros estudos, onde nesta fase é alto o título de anticorpos antiToxoplasma gondii $i^{2638}$.

A análise por faixa etária mostrou uma evolução, variando a prevalência conforme o tempo de exposição, com correlação direta entre eventos $(p<0,001)$. Neste caso, foi possível estimar uma incidência anual de soroconversão de $2 \%$, usando-se a inclinação da curva de tendência do qui-quadrado. Investigações recentes corroboram com nossos dados, como na Slovakia, onde se verificou um aumento da taxa de soropositividade de acordo com a idade (35,4\%), principalmente entre 0 grupo de $35-44$ $\operatorname{anos}^{42}$ e na República Democrática de São Tomé e Príncipe, onde a tendência maior foi no grupo com idade entre $35-45$ ou $>45$ anos, atribuída a uma longa exposição aos fatores de risco ${ }^{13}$.

Quando se empregou o teste de avidez foram identificados casos sugestivos de infecção recente, dados condizentes com outros estudos $^{3843}$, que permitiram estimar uma incidência real de 2,4\% de soroconversão ao ano, semelhante aos valores detectados pela evolução sorológica por faixa etária. 0 teste de avidez e o emprego de outros métodos se tornam especialmente importante quando se tem resultados de ELISA IgM residuais ${ }^{17} 32$, contudo, em dois casos, o teste de avidez e os demais ensaios sorológicos não permitiram a identificação precisa do período de infecção, havendo a necessidade do emprego de outros métodos diagnósticos como o isolamento ou deteç̧ão de ácidos nucléicos do agente em líquido amniótico ${ }^{15}$.

Embora o teste de avidez venha contribuir no esclarecimento do diagnóstico da infecção aguda pelo Toxoplasma gondii, em alguns pacientes ocorre persistência de anticorpos de baixa avidez por muitos meses contra o lisado de células antigênicas do toxoplasma ${ }^{3135}$. Da mesma forma, devido a maturação dos anticorpos IgG ocorrer em períodos diferentes, pode haver erros na interpretação dos resultados. Por isso, o teste de avidez, não deve ser utilizado como parâmetro para conclusão do diagnóstico da infecção ${ }^{832}{ }^{35}$. Além disso, os dados de positividade por faixa etária mostraram que os fatores de risco para contrair a toxoplasmose nesta região não parecem ter sofrido alterações, com uma evolução regular da soroprevalência, sem inflexões abruptas sugestivas de surto epidêmico.

Os dados estimados tanto pelo teste de avidez quanto pela soropositividade por faixa etária mostraram uma incidência expressiva da toxoplasmose nas gestantes de Cascavel, o que implica em aprimoramento dos procedimentos na avaliação pré-natal das gestantes atendidas no laboratório municipal. 0 protocolo existente prevê o diagnóstico laboratorial da toxoplasmose através da realização de apenas um teste, sem acompanhamento seqüencial das gestantes. Na prática, este protocolo deveria contemplar outros testes complementares em especial daquelas gestantes que não tiveram contacto com o agente (soronegativas) e que poderiam apresentar uma infecção por soroconversão.

Estudos comprovam que tanto na prevenção da infecção congênita ${ }^{28}{ }^{32}$ como em surtos epidêmicos ${ }^{9}$ um teste sorológico realizado isoladamente não é suficiente para excluir a infecção pelo Toxoplasma gondii. Ainda assim, os resultados dos exames feitos no laboratório municipal de Cascavel são bem aceitos pela classe médica devido à alta sensibilidade e especificidade do ELISA IgG comercial, comprovadas pelos testes complementares realizados no IMTSP.

Vários trabalhos publicados mostram uma discordância de resultados devido à diferença entre os métodos empregados, como por exemplo, no surto epidêmico da toxoplasmose ocorrido em Santa Isabel do Ivaí no Paraná, onde as variações no número de casos positivos para IgM foram discrepantes, inicialmente observando-se 426 casos $^{10} \mathrm{e}$ em análises posteriores 176 casos $^{9}$. No presente estudo, os resultados entre os testes realizados no Paraná e em São Paulo mostraram uma boa concordância, sensibilidade e especificidade.

Uma medida simples e de fácil exequiibilidade para controlar os casos de toxoplasmose congênita em Cascavel seria, como sugerem Liesenfeld e $\mathrm{cols}^{27}$, a criação de um programa pré-natal com triagem sistemática mensal e o emprego de vários testes. A melhor opção com diagnóstico mais adequado da doença na gestante é 0 emprego de um painel de testes sorológicos, incluindo a avidez de IgG. Esta abordagem serviria de triagem para emprego de outros exames parasitológicos fetais, que envolvem risco, mas que visam à detecção do Toxoplasma gondii em amostras de líquido amniótico e sangue periférico a partir do isolamento em cultivo celular ou inoculação em camundongos, ou então, métodos moleculares mais sofisticados ${ }^{15}$.

Muitos trabalhos evidenciam que a educação sanitária como medida preventiva para os riscos de aquisição da toxoplasmose congênita pode ser um componente importante na prática obstétrica. Para muitas gestantes os fatores de risco, bem como os sinais e sintomas da infecção não são reconhecidos, sendo essencial o papel do obstetra no diagnóstico e prevenção da infecção. Em alguns países essa abordagem é esporádica em gestantes, como é o caso dos Estados Unidos ${ }^{4}$, já na França, Áustria, Finlândia, e Noruega medidas educacionais são incorporadas à rotina médica, reduzindo em torno de $50 \%$ as taxas de infecção ${ }^{5839} 40$. No Brasil, há necessidade de sensibilização dos profissionais de saúde envolvidos com a gestante e o recém nato, e de confirmação dos resultados através um painel de testes sorológicos para prevenir os casos de toxoplasmose aguda com risco de infecção congênita.

A avaliação criteriosa de testes sorológicos pode gerar dados úteis para a prevenção e a instituição de protocolos para deteç̧ão da infecção em grupos de risco, incluindo o teste de avidez de IgG. Estudos transversais simples como este podem facilitar a interpretação do diagnóstico, resultando em propostas de ações mais adequadas e monitoráveis.

\section{AGRADECIMENTOS}

A Roselaine Pereira Alvim Cardoso, Laboratório de Protozoologia do IMTSP (LIM 49), Nely Norder Tschurtschenthaler, Laboratório Municipal de Cascavel-PR, Secretaria de Saúde do Município de Cascavel-PR. 


\section{REFERÊNCIAS}

1. Adesiyun AA, Gooding R, Ganta K, Seepersadsingh N, Ramsewak S. Congenital toxoplasmosis in two health institutions in Trinidad. West Indian Medical Journal 56: 166-170, 2007.

2. Ambroise-Thomas P, Schweiter M, Pinon JM, Thiebaugeorges O. La prévention de la toxoplasmose congénitale em France. Evaluation des risques. Résultats et perspectives du dépistage antenatal et du suivi du nouveau né. Bulletin de l'Académie Nationale de Médicine 185: 665-683, 2001.

3. Bóia MN, Carvalho-Costa FA, Sodré FC, Pinto GM, Amendoeira MR. Seroprevalence of Toxoplasma gondii infection among Indian people living in Iaureté, São Gabriel da Cachoeira, Amazonas, Brazil. Revista do Instituto de Medicina Tropical. São Paulo 50: 17-20, 2008.

4. Boyer KM, Holfels E, Roizen N, Swisher C, Mack D, Remington J, Withers S, Meier P, McLeod R. Risk factors for Toxoplasma gondii infection in mothers of infants with congenital toxoplasmosis: implications for prenatal management and screening. American Journal of Obstetrics and Gynecology 192: 564-571, 2005.

5. Boyer KM, McLeod R. Toxoplasma gondii (toxoplasmosis). In: Long SS, Pickering LK, Prober CG (eds) Principles and practice of pediatric infectious diseases. $2^{\text {nd }}$ edition. Churchill Livingstone, New York, p. 1303-1322, 2003.

6. Camargo ME, Leser PG. Diagnostic information from serological tests in human toxoplasmosis. II Evolutive study of antibodies and serological patterns in acquired toxoplasmosis, as detected by hemagglutination, complement fixation, IgG and IgM-immunofluorescence tests. Revista do Instituto de Medicina Tropical 18: 227-238, 1976 .

7. Castilho-Pelosso MP, Falavigna DLM, Araújo SM, Falavigna-Guilherme AL. Monitoramento de gestantes com toxoplasmose em serviços públicos de saúde. Revista da Sociedade Brasileira de Medicina Tropical 38: 532-533, 2005.

8. Coura JR. Dinâmica das doenças infecciosas e parasitárias. Volume I. Guanabara Koogan, Rio de Janeiro, p. 815-832, 2005.

9. De Moura L, Bahia-Oliveira LM, Wada MY, Jones JL, Tuboi SH, Carmo EH, Ramalho WM, Camargo NJ, Trevisan R, Graça RM, Silva AJ, Moura I, Dubey JP, Garrett DO. Waterborne toxoplasmosis, Brazil, from field to gene. Emerging Infectious Diseases 12: 326-329, 2006.

10. Dias RAF, Freire RL. Surtos de toxoplasmose em seres humanos e animais. Semina: Ciências Agrárias 26: 239-248, 2005.

11. Dubey JP, Beattie, CP. Toxoplasmosis of animals and man. Boca Raton, CRC Press, Flórida, 1998.

12. Dunn D, Wallon M, Peyron F, Petersen E, Peckham C, Gilbert R. Mother-tochild transmission of toxoplasmosis: risk estimates for clinical counselling. The Lancet 353: 1829-1833, 1999.

13. Fan CK, Hung CC, Su KE, Chiou HY, Gil V, Ferreira MC, Tseng LF. Seroprevalence of Toxoplasma gondii infection among inhabitants in Democratic Republic of Sao Tome and Principe. Transactions of the Royal Society of Tropical Medicine and Hygiene 101: 1157-1158, 2007.

14. Ferreira AW, Ávila, SLM. Diagnóstico laboratorial das principais doenças infecciosas e auto-imunes. $2^{\text {a }}$ Edição. Guanabara Koogan, Rio de Janeiro, p. 279,2001

15. Ferreira IM, Vidal JE, Costa-Silva TA, Meira CS, Hiramoto RM, Oliveira ACP, Pereira-Chioccola VL. Toxoplasma gondii: genotyping of strains from Brazilian AIDS patients with cerebral toxoplasmosis by multilocus PCR-RFLP markers. Experimental Parasitology 118: 221-227, 2008.

16. Ferreira M, Bicheri MCM, Nunes MB, Ferreira CCM. Diagnóstico laboratorial da infecção por Toxoplasma gondii na gestação. Revista Brasileira de Análises Clínicas 39: 37-38, 2007.

17. Figueiró-Filho EA, Lopes AHA, Senefonte FRA, Souza Júnior VG, Botelho CA, Figueiredo MS, Duarte G. Toxoplasmose aguda: estudo da frequiência, taxa de transmissão vertical e relação entre os testes diagnósticos materno-fetais em gestantes em estado da Região Centro-Oeste do Brasil. Revista Brasileira de Ginecologia e Obstetrícia 27: 442-449, 2005.

18. Francis JM, Joynson DH. Duration of specific immunoglobulin A antibody following acute toxoplasmosis as determined by enzyme immunoassay and immunosorbent agglutination assay. European Journal of Clinical Microbiology and Infectious Diseases 12: 556-559, 1993.
19. Fricker-Hidalgo H, Saddoux C, Suchel-Jambon AS, Romand S, Foussadier A, Pelloux H, Thulliez P. New Vidas assay for Toxoplasma-specific IgG avidity: evaluation on 603 sera. Diagnostic Microbiology and Infectious Diseases 56: 167-172, 2006

20. Golkar M, Azadmanesh K, Khalili G, Khoshkholgh-Sima B, Babaie J, Mercier C, Brenier-Pinchart MP, Fricker-Hidalgo H, Pelloux H, Cesbron-Delauw MF. Serodiagnosis of recently acquired Toxoplasma gondii infection in pregnant women using enzyme-linked immunosorbent assays with a recombinant dense granule GRA6 protein. Diagnostic Microbiology and Infectious Diseases 61: 31-39, 2008.

21. Hedman K, Lappalainen M, Seppäiä I, Mäkelä 0 . Recent primary toxoplasma infection indicated by a low avidity of specific IgG. The Journal of Infectious Diseases 159: 736-740, 1989.

22. Hill D, Dubey JP. Toxoplasma gondii: transmission, diagnosis and prevention. Clinical Microbiology and Infection 8: 634-640, 2002.

23. Iqbal J, Khalid N. Detection of acute Toxoplasma gondii infection in early pregnancy by IgG avidity and PCR analysis. Journal of Medical Microbiology 56: 1495-1499, 2007

24. Jenun PA, Stray-Pedersen B. Development of specific immunoglobulins G, M and A following primary Toxoplasma gondii infection in pregnant women. Journal of Clinical Microbiology 36: 2907-2913, 1998.

25. Korhonen MH, Brunstein J, Haario H, Katnikov A, Rescaldani R, Hedman K. A new method with general diagnostic utility for the calculation of immunoglobulin $\mathrm{G}$ avidity. Clinical Diagnostic Laboratory Immunology 6: 725-728, 1999.

26. Leser PG, Rocha LSA, Moura MEG, Ferreira AW. Comparison of semi-automatized assays for anti-T. gondii IgG detection in low-reactivity serum samples: importance of the results in patient counseling. Jornal Brasileiro de Patologia e Medicina Laboratorial 39: 107-110, 2003.

27. Liesenfeld O, Montoya JG, Tathineni NJ, Davis M, Brown Jr BW, Cobb KL, Parsonnet J, Remington JS. Confirmatory serologic testing for acute toxoplasmosis and rate of induced abortions among women reported to have positive Toxoplasma immunoglobulin M antibody titers. American Journal of Obstetrics \& Gynecology 184: 140-145, 2001.

28. Lopes FMR, Gonçalves DD, Breganó RM, Freire RL, Navarro IT. Toxoplasma gondii infection in pregnancy. The Brazilian Journal of Infectious Diseases 11: 496-506, 2007.

29. Mazzola A, Casuccio A, Romano A, Schimmenti MG, Titone L, Di Carlo P. Diagnostic problems and postnatal follow-up in congenital toxoplasmosis. Minerva Pediátrica 59: 207-213, 2007.

30. Montoya JG, Huffman HB, Remington JS. Evaluation of the immunoglobulin G avidity test for diagnosis of toxoplasmic lymphadenopatyy. Journal of Clinical Microbiology 42: 4627-4631, 2004.

31. Montoya JG, Liesenfeld O. Toxoplasmosis. The Lancet 363: 1965-1976, 2004.

32. Montoya JG, Liesenfeld O, Kinney S, Press C, Remington JS. VIDAS Test for avidity of Toxoplasma - specific immunoglobulin $\mathrm{G}$ for confimatory testing of pregnant women. Journal of Clinical Microbiology 40: 2504-2508, 2002.

33. Montoya JG, Rosso F. Diagnosis and management of toxoplasmosis. Clinics in Perinatology 32: 705-726, 2005.

34. Petersen E, Borobio MV, Guy E, Liesenfeld O, Moroni V, Naessens A, Spranzi E, Thulliez P. European Multicenter for determination of Toxoplasma gondiispecific Immunoglobulin $\mathrm{G}(\mathrm{IgG})$ and $\operatorname{IgM}$ and $\operatorname{IgG}$ Avidity Index. Journal of Clinical Microbiology 43: 1570-1574, 2005.

35. Piergili FD. Problems and limitations of convencional and innovative methods for diagnosis of toxoplasmosis in humans and animals. Parassitologia 46: 177-181, 2004.

36. Press C, Montoya JG, Remington JS. Use of a single serum simple for diagnosis of acute toxoplasmosis in pregnant women and other adults. Journal of Clinical Microbiology 43: 3481-3483, 2005.

37. Reiche EM, Morimoto HK, Faria GN, Hisatsugo KR, Geller L, Gomes ACLF, Inoue HY, Rodrigues G, Matsuo T. Prevalence of American trypanosomiasis, syphilis, toxoplasmosis, rubella, hepatitis B, hepatitis C, human immunodeficiency virus infection, assayed through serological tests among pregnant patients, from 1996 to 1998, at the Regional University Hospital Norte do Paraná. Revista da Sociedade Brasileira de Medicina Tropical 33: 519-527, 2000. 
38. Reis MM, Tessaro MM, D'Azevedo PA. Toxoplasma-IgM and IgG Avidity in single samples from areas with a high infection rate can determine the risk of mother-to-child transmission. Revista do Instituto de Medicina Tropical 48: 93-98, 2006.

39. Remington JS, Mcleod R, Thulliez P, Desmonts G. Toxoplasmosis. In: Remington JS, Klein JO (eds) Infectious diseases of the fetus and newborn infant, $5^{\text {th }}$ edition. WB Saunders, Philadelphia. p. 205-346. 2001.

40. Rorman E, Zamir CS, Rilkis I, Ben-David H. Congenital toxoplasmosis-prenatal aspects of Toxoplasma gondii infection. Reproductive Toxicology 21: 458-472, 2006.

41. Sensini A. Toxoplasma gondii infection in pregnancy: opportunities and pitfalls of serological diagnosis. Clinical Microbiology and Infection 12: 504-512, 2006
42. Studenicová C, Ondriska F, Holková R. Seroprevalence of Toxoplasma gondii among pregnant women in Slovakia. Epidemiologie, Mikrobiologie, Imunologie 57: 8-13, 2008.

43. Tanyuksel M, Guney C, Araz E, Saracli MA, Doganci L. Performance of the immunoglobulin $\mathrm{G}$ avidity and enzyme immunoassay $\mathrm{Ig} / \mathrm{IgM}$ screening tests for differentiation of the spectrum of toxoplasmosis. Journal of Microbiological Methods 42: 211-215, 2004.

44. Varella IS, Wagner MB, DarelaAC, Nunes LM, Muller RW. Prevalência de soropositividade para toxoplasmose em gestantes. Jornal de Pediatria 79: 69-74, 2003.

45. Venkatesan P, Wakelin D. ELISAs for parasitologists: or lies damned lies and ELISAs. Parasitology Today 9: 228-232, 1993.

46. Wong SY, Remington JS. Toxoplasmosis in pregnancy. Clinical Infectious Diseases 18: 853-861, 1994 